\title{
Molecular and cellular biology of cerebral arteriovenous malformations: a review of current concepts and future trends in treatment
}

\author{
*Leonardo Rangel-Castilla, M.D., Jonathan J. Russin, M.D., \\ Eduardo Martinez-del-Campo, M.D., Hector Soriano-Baron, M.D., \\ Robert F. Spetzler, M.D., and Peter Nakaji, M.D.
}

Division of Neurological Surgery, Barrow Neurological Institute, St. Joseph's Hospital and Medical Center, Phoenix, Arizona

\begin{abstract}
Object. Arteriovenous malformations (AVMs) are classically described as congenital static lesions. However, in addition to rupturing, AVMs can undergo growth, remodeling, and regression. These phenomena are directly related to cellular, molecular, and physiological processes. Understanding these relationships is essential to direct future diagnostic and therapeutic strategies. The authors performed a search of the contemporary literature to review current information regarding the molecular and cellular biology of AVMs and how this biology will impact their potential future management.

Methods. A PubMed search was performed using the key words "genetic," "molecular," "brain," "cerebral," "arteriovenous," "malformation," "rupture," "management," “embolization," and "radiosurgery." Only Englishlanguage papers were considered. The reference lists of all papers selected for full-text assessment were reviewed.

Results. Current concepts in genetic polymorphisms, growth factors, angiopoietins, apoptosis, endothelial cells, pathophysiology, clinical syndromes, medical treatment (including tetracycline and microRNA-18a), radiation therapy, endovascular embolization, and surgical treatment as they apply to AVMs are discussed.

Conclusions. Understanding the complex cellular biology, physiology, hemodynamics, and flow-related phenomena of AVMs is critical for defining and predicting their behavior, developing novel drug treatments, and improving endovascular and surgical therapies.
\end{abstract}

(http://thejns.org/doi/abs/10.3171/2014.7.FOCUS14214)

\section{KEY WORDS • molecular • cellular biology • arteriovenous malformation • medical treatment $\quad$ future trends}

A RTERIOVENOUS malformations (AVMs) are vascular lesions characterized by a tangle of abnormal arteries and veins that directly shunt blood from the arterial to the venous circulation. Cerebral AVMs occur most commonly sporadically but can be associated with genetic disorders. $4,8,15,36,48,58$ The reported incidence of AVMs is $1.34 / 100,000$ person-years, with a prevalence of 10 to $18 / 100,000$, and they account for approximately

Abbreviations used in this paper: ACVRL1 = activin receptorlike kinase 1; ANG = angiopoietin; ANGPTL = ANG-like; $\mathrm{AVM}=$ arteriovenous malformation; $\mathrm{BDNF}=$ brain-derived neurotrophic factor; $\mathrm{BEC}=$ brain endothelial cell; $\mathrm{ENG}=$ endoglin; $\mathrm{HHT}=$ hereditary hemorrhagic telangiectasia; $\mathrm{ICH}=$ intracranial hemorrhage; LPS/sTF = lipopolysaccharide and soluble tissue factor conjugate; MIF = macrophage migration inhibitory factor; miR-18a = microRNA-18a; MMP = matrix metalloproteinase; SNP = single nucleotide polymorphism; SRS = stereotactic radiosurgery; $\mathrm{TGF}=$ transforming growth factor; TSP-1 = thrombospondin- 1 ; VEGF $=$ vascular endothelial growth factor. work.

* Drs. Rangel-Castilla and Russin contributed equally to this
$1.4 \%-2 \%$ of all hemorrhagic strokes..$^{10,36,46}$ Arteriovenous malformations are diagnosed incidentally in $0.05 \%$ of all neuroimaging studies.

Intracranial hemorrhage $(\mathrm{ICH})$ is the most severe and most common clinical presentation of cerebral AVMs. Risk factors that have been associated with AVM rupture include certain genetic mutations, intranidal aneurysms, exclusive deep venous drainage, restricted venous outflow, and deep or infratentorial location. ${ }^{1,26,36}$ The annual risk of rupture is $2 \%-4 \%$, manifesting as the initial symptom in $37 \%-71 \%$ of patients, with an incidence of $0.51 / 100,000$. After hemorrhage, the risk of recurrent hemorrhage during the 1 st year is $6 \%-18 \%$, returning to $4 \%$ after this period. Mortality is reported at $10 \%$ after hemorrhage, and residual major disability occurs in $20 \%-30 \%$ of patients. ${ }^{7,9,10}$ $14,15,18-20,29,36,40,44,55,57$

Feeding artery pressures, compartmentalization, venous drainage, flow phenomena, and vascular steal all contribute to the complex physiology of cerebral AVMs. Intranidal vessels are exposed to abnormally high blood flow and shear forces that activate molecular pathways in 


\section{Rangel-Castilla et al.}

smooth muscle cells and brain endothelial cells (BECs), leading to proliferation and vascular remodeling. ${ }^{32,33,50,54}$ Microscopic animal models have shown that cerebral AVMs have a number of pathological changes present in nidal vessels. These changes include heterogeneously thickened vessel walls, splitting of the elastic lamina, thickened endothelial layers, endothelial cushions, lack of tight and adherent junctions, loss of endothelial continuity, and filopodia (microspikes) directed into the lumen. ${ }^{51}$

Over the last 2 decades, new genetic, molecular, and cellular factors have been demonstrated to be involved in the process of formation, growth, and rupture of AVMs. The goal of this work was to compile and analyze new evidence regarding these processes and investigate consequent potential future therapeutic alternatives.

\section{Methods}

A comprehensive review of English-language literature was performed on PubMed using the key words "brain," "cerebral," "arteriovenous," "malformation," "management," "embolization," "radiosurgery," "rupture," "genetic," and "molecular." Additional articles were located by cross-referencing articles encountered initially through PubMed searches. Inclusion criteria comprised articles (case reports, case series, meta-analyses, clinical trials, literature reviews, molecular studies, animal models, and guidelines) originating from peer-reviewed literature and discussing the molecular and cellular biology, the risk factors, clinical presentation, diagnostic tests, management, outcomes, and complications of patients with cerebral AVMs.

Conceptually, this review will examine the biology of syndromic AVMs for which there may be a more discernable pathway than for sporadic ones. Then the factors potentially involved in AVM formation will be reviewed. The processes involved in AVM progression, including the important events of growth and rupture, will be discussed. Current AVM treatment paradigms will next be covered. Lastly, potential treatment avenues that take advantage of AVM biology as it is currently known will be explored (Fig. 1).

\section{Molecular and Cellular Biology Associated With Syndromic AVMs}

The majority of cerebral AVMs are sporadic; however, a minority of patients will be diagnosed with a genetic mutation (e.g., hereditary hemorrhagic telangiectasia [HHT] $).{ }^{16,35,50}$ Identification of genetic mutations associated with cerebral AVM formation has facilitated the development of animal models that have provided new insights into the etiology of these lesions. ${ }^{9,34,39,50}$ Although inheritable mutations are most frequently discussed, environmental factors are also believed to play an important role in single allele mutations. ${ }^{23}$

Osler-Weber-Rendu syndrome, or HHT, is the most common syndrome associated with AVMs. It is an autosomal-dominant vascular disease caused by haplo-insufficiency of the transforming growth factor (TGF)- $\beta$ pathway signaling genes $E N G, A C V R L 1$, and SMAD4. It is characterized clinically by mucocutaneous telangiectasias, with the presence of single or multiple AVMs in $9 \%-25 \%$ of patients..$^{35,42}$ The phakomatosis cerebrofacial arteriovenous metameric syndrome (CAMS) consists of brain and orbit AVMs with retinal or retrobulbar lesions. Some patients with complete expression manifest high-flow maxillofacial or mandibular AVMs, manifesting life-threatening epistaxis or gingival hemorrhage. ${ }^{3}$ Cervical cutaneomeningospinal angiomatosis, or Cobb's syndrome, is a rare somatic disorder presenting with spinal AVMs and abnormal platelet endothelial cell adhesion molecule (PECAM-1), smooth muscle actin, VEGF (vascular endothelial growth factor), and matrix metalloproteinase (MMP)-9 expression. ${ }^{13}$ Other diagnoses less frequently associated with AVMs include ataxia telangiectasia, Sturge-Weber syndrome, and cerebral autosomaldominant arteriopathy with subcortical infarcts and leukoencephalopathy (CADASIL). ${ }^{33,46}$ While these represent a variety of associations with AVM formation, they do not yet define a common pathway.

\section{AVM Formation}

Arteriovenous malformations have been associated with several genetic mutations, resulting in their pathogenesis. These genetic mutations alter inflammatory factors, angiogenesis, vasculogenesis, and structural proteins. ${ }^{35,48}$ More than 860 genes are now known to be upregulated (300) and downregulated (560) in cerebral AVMs. ${ }^{33}$ Single nucleotide polymorphisms (SNPs) are DNA sequence variations that differ between members of the same species. SNPs of certain angiogenic factors were first associated with sporadic cerebral AVMs and subsequently with their risk of rupture. ${ }^{37}$ Some specific molecules affected by SNPs are TGF- $\beta$, an extracellular glycosylated protein that suppresses the effects of interleukins and is critical in de novo AVM formation; ${ }^{32}$ brain-derived neurotrophic factor (BDNF), a protein that supports survival, development, and function of neurons, ${ }^{55}$ interleukin-6 (IL-6), which contributes to vascular wall instability by stimulating the release of MMP; $;^{32,33,38}$ and angiopoietin-like 4 (ANGPTL4), a glycoprotein believed to be involved in angiogenesis (Table 1). ${ }^{31}$ Vascular endothelial growth factor is a critical signaling molecule that regulates angiogenesis and is typically suppressed in normal adult vasculature. VEGF has a potent mitotic effect and is highly expressed in children with recurrent AVMs. ${ }^{6}$ Cerebral hypoxia and ischemia result in VEGF secretion by astrocytes. Following the release of hypoxia-induced factors, a response element contained in the VEGF gene promoters enables a 30 -fold increase in VEGF within minutes. ${ }^{21,32}$ VEGF-A is primarily expressed in astroglia adjacent to the AVM nidus, while VEGF-C and VEGF-D are highly expressed within large nidi and are believed to contribute to development.

Angiopoietins (ANGs) are vascular growth factors that regulate pericyte and smooth muscle precursors involved in angiogenesis and vascular stability. ANG1 promotes cellular interaction providing vessel stability and has been found to have decreased levels in AVM patients. ANG2 has a role in deconstructive signaling, promoting 


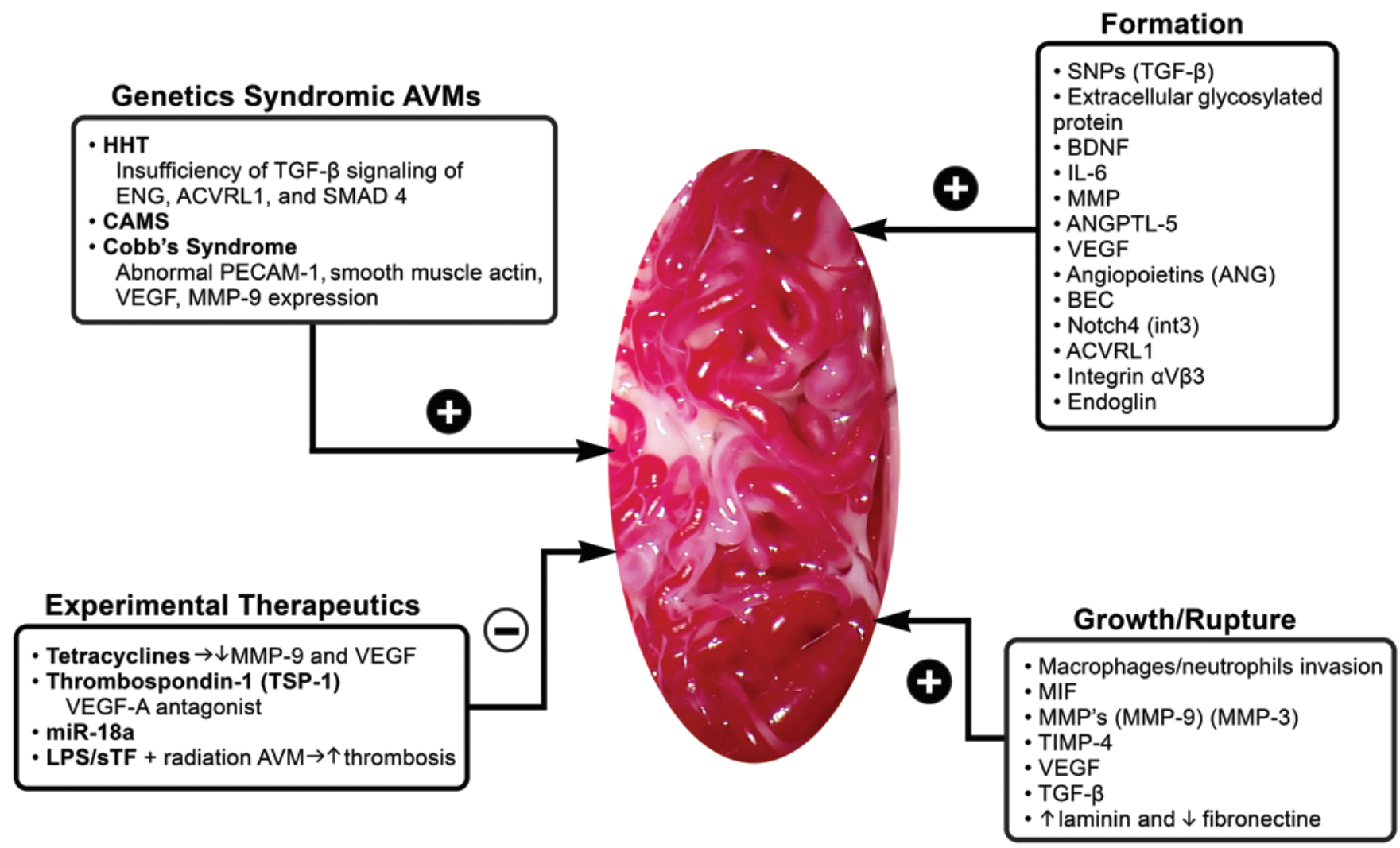

FIG. 1. Diagram showing different genetic, molecular, and cellular biology components that contribute to the formation, growth, and rupture of AVMs and experimental treatment. ACVRL1 = activin A receptor type II-like; ANGPTL-5 = angiopoietin-like 5; $\mathrm{BDNF}=$ brain-derived neurotrophic factor; $\mathrm{BEC}=$ brain endothelial cell; CAMS = cerebrofacial arteriovenous metameric syndrome; ENG = endoglin; HHT = hereditary hemorrhagic telangiectasia; IL-6 = interleukin-6; LPS/sTF = lipopolysaccharide and soluble tissue factor conjugate; MIF = macrophage-migration inhibitory factor; miR-18a = microRNA-18a; MMP = matrix metalloproteinase; PECAM-1 = platelet endothelial cell adhesion molecule; SMAD = family member 4; SNP = single nucleotide polymorphism; TGF- $\beta=$ transforming growth factor- $\beta$; TIMP = tissue inhibitor of MMP-4; VEGF = vascular endothelial growth factor; $\downarrow=$ decreased; $\uparrow=$ increased.

TABLE 1: Single nucleotide polymorphisms associated with brain AVMs*

\begin{tabular}{|c|c|c|}
\hline Molecule & SNP & Associated Effect \\
\hline TGF- $\beta 2$ & $-879 \mathrm{G} / \mathrm{G}$ & increased risk for BAVM \\
\hline TGFR- $\beta 2$ & $-875 \mathrm{~A} / \mathrm{G}$ & increased risk for BAVM \\
\hline IL-17A & $-197 \mathrm{G} / \mathrm{A}$ & together with TGFR- $\beta 2-875 \mathrm{~A} / \mathrm{G}$, increased risk for ICH \\
\hline BDNF & rs6265 (Val66Met) & $\begin{array}{l}\text { decreased BDNF secretion \& poor outcome after neurological injury \& } \\
\text { worse surgical outcome in unruptured BAVMs }\end{array}$ \\
\hline ANGPTL4 & rs11672433 & increased risk for BAVM \\
\hline MMP-3 & rs522616 (-709 A/G) & 2-fold increased transcription \\
\hline MMP-9 & rs9509 & highly associated w/ ICH \\
\hline IL-1a & $-889 C>T$ & increased risk for BAVM \\
\hline IL-6 & $-174 \mathrm{G} / \mathrm{C}$ & associated w/ TNF-a-238 G/A for increased risk of ICH \\
\hline ACVRL1 & IVS3-35 A/G & increased risk for BAVM \\
\hline NA & rs1333040 C/T & $\begin{array}{l}\text { located on 9p21 arm; associated w/ BAVM; deep venous drainage, } \\
\text { seizures \& ICH are more frequent }\end{array}$ \\
\hline
\end{tabular}

\footnotetext{
* ANGPTL4 = angiopoietin-like 4; AVCRL1 = activin receptor-like kinase 1; BAVM = brain AVM; BDNF = brain-derived neurotrophic factor; IL = interleukin; IVS = intervening space; $\mathrm{MMP}=$ matrix metalloproteinase; $\mathrm{NA}$ = not available; $\mathrm{TGF}=$ transforming growth factor; TGFR = TGF receptor; TNF = tumor necrosis factor.
} 


\section{Rangel-Castilla et al.}

remodeling, and vessel destabilization. It has been reported to be upregulated in cerebral AVM patients with ANG2 mRNA levels being increased by up to $30 \%$. However, it is believed that to develop a cerebral AVM, ANG2 and VEGF work synergistically and both must be overexpressed. ${ }^{21,33}$

Genes, molecules, and structural proteins located in BECs are believed to be intimately associated with the development of cerebral AVMs. Neurogenic locus Notch4 is a member of a family of transmembrane proteins with repeats of extracellular endothelial growth factor (EGF). Bone morphogenetic protein (BMP) signaling is linked to Notch4 modulation and it is thought that deviation from normal expression in this relationship can contribute to AVM formation. Deficiency of matrix G1a protein $\left(\mathrm{MGP}^{-/-}\right)$in animal models induces expression of activin receptor-like kinase 1 (ACVRL1). ACVRL1 will inhibit BMP and induce Notch ligands, resulting in deregulation of endothelial differentiation and AVM development in MGP null animal models. ${ }^{56}$ Activation of Notch4 (int-3) in the endothelium of animal models during brain development has been associated with AVM formation; it can be activated using a tetracycline-regulatable system. It has been demonstrated that int- 3 activation alone is sufficient to induce and sustain the growth of abnormally large vasculature and shunting, which are the hallmarks of AVMs. Int-3 expression results in widespread enlargement of the microvasculature, which coincides with a reduction in the capillary density. The Notch pathway is a molecular regulator of brain AVMs pathogenesis in mice, and this connection offers hope that their regression might be possible by targeting the causal molecular pathway. ${ }^{34}$

Aside from initiation, it is believed that cell-cell interactions may be important to AVM growth and progression. Integrins are heterodimeric transmembrane cell-surface adhesion receptors that mediate matrix and cell-cell interactions, transducing signals that regulate multiple vital cellular functions. Integrin $\alpha \mathrm{V} \beta 3$ has increased expression in cerebral AVMs..$^{16,33,43}$ Endoglin (ENG) is a glycoprotein located on cellular surfaces crucial for angiogenesis. High levels of endoglin enhance the effects of ACVRL1 over endothelial proliferation. Both proteins are part of the TGF- $\beta$ complex, and genetic mutations on ENG and ACVRL1 are both associated with HHT and arteriovenous fistulas. ${ }^{7,33,43}$ Arteriovenous malformation BEC turnover has been described to be somewhere between normal BECs and those in developing tumors, with aberrant functions. These cells are believed to undergo rapid proliferation and migration, producing aberrant tubular structures, due to deregulation in vasculogenesis and angiogenesis. , $, 17,33,58^{-10}$

\section{AVM Growth and Rupture}

A role for inflammation and extracellular matrix remodeling in AVM growth and rupture has been postulated. Inflammatory cells are frequently identified in the vascular wall of cerebral AVM vessels. Macrophages and neutrophils tend to invade AVM tissue even in the absence of radiographically evident hemorrhage. Relative neutrophilia and increases in macrophage migration inhibitory factor (MIF) both appear to contribute to the instability of AVM nidal vessels, contributing to apoptosis and possibly rupture. Elevated MIF levels are primarily found in the vascular endothelium and adventitia, while apoptotic cells are concentrated in the smooth muscle layer., ${ }^{5,21}$

Matrix metalloproteinases also appear to play a key role in the growth and rupture of cerebral AVMs. ${ }^{4,21,24,33,47}$ These are proteolytic enzymes that degrade pericellular substances, resulting in vascular destabilization and altered angiogenesis. ${ }^{18,33}$ Starke et al. found that plasma levels of MMP-9 were significantly elevated over controls at baseline, increased significantly immediately after surgery, and decreased to pretreatment levels during followup. ${ }^{47}$ Single nucleotide polymorphisms of MMP-9 and tissue inhibitor of MMP-4 (TIMP-4) are also associated with increased risk of rupture in patients with cerebral AVMs. This was demonstrated in patients with AVM who underwent genotyping analysis. ${ }^{49}$ VEGF has been associated with AVM rupture through an increased expression of MMP-9. Rupture of cerebral AVMs has also been associated with overexpression of MMP-3. It is believed that the binding of transcription factor C-MYB to the area around rs522616 SNP results in the overexpression of MMP-3. ${ }^{21}$ Table 1 summarizes the most relevant SNPs associated with cerebral AVMs and their risk for rupture.

Brain endothelial cells have a high proliferation rate with reduced apoptotic response to inflammatory mediators such as TGF- $\beta$. Angiogenic factors, like VEGF, are not normally produced by quiescent brain vasculature, but are by AVM-BECs. ${ }^{43}$ In contrast to mature vessels, immature vessels are associated with a fibronectin-rich matrix deficient in laminin. The high concentration of laminin and the absence of fibronectin in AVM vessels favor the hypothesis that they are relatively mature vessels. This vessel maturity is believed to contribute to the vascular resilience in the face of hemorrhage. However, one observes clinically that while the vessels of AVMs are relatively robust, some are fragile to handling and do not coagulate normally, and clearly they develop areas of weakness, which results in clinical hemorrhage. It is likely that multiple mechanisms including inflammation, remodeling, and BEC abnormalities contribute to their tendency to exhibit hemorrhage.

\section{AVM Treatment}

\section{Current Management}

A recent meta-analysis presented by van Beijnum et al. included 13,698 patients with ruptured and unruptured cerebral AVMs. ${ }^{53}$ They reported obliteration rates of $96 \%$, $38 \%$, and $13 \%$ by microsurgical resection, stereotactic radiosurgery (SRS), and endovascular embolization, respectively. Microsurgical resection is currently recommended for Spetzler-Ponce Class A or Spetzler-Martin Grade I or II AVMs based on pooled analysis. ${ }^{44,45}$ Spetzler-Ponce Class B or Spetzler-Martin Grade III lesions are a heterogeneous grouping and current recommendations are for resection with special consideration for combination therapy. For Spetzler-Ponce Class C or SpetzlerMartin Grade IV and V AVMs, palliative treatment is 
recommended in the setting of progressive neurological decline and/or recurrent hemorrhages. A combination of SRS, embolization, and microsurgery may be used in the palliative management of Spetzler-Ponce Class $\mathrm{C}$ lesions. ${ }^{15,22,36,41}$ Given that the large majority of high-grade lesions cannot be treated without relatively high morbidity and mortality using current surgical and radiosurgical paradigms, new cellular and molecular biological therapies are under development aiming toward radiosensitization, vascular targeting, and remodeling therapies..$^{27,43}$ The current AVM treatment paradigm does not take into consideration any special factors related to the genetics or molecular constitution of the specific patient who has an AVM. It is reasonable to think at some point that a better understanding of regulatory factors and pathways may allow us to modify the natural history away from rupture.

\section{Experimental Therapies}

Given that the process of AVM rupture is believed to be related to the AVM's capacity for local vascular remodeling, drugs that impede this process form a group that are theoretically attractive as therapeutic agents. Tetracyclines are a class of antibiotics that have the potential to prevent pathological vascular remodeling and therefore potentially decrease the risk of AVM rupture. ${ }^{12}$ Doxycycline has been shown to decrease cerebral MMP-9 activity and angiogenesis induced by VEGF. ${ }^{17,25} \mathrm{~A} \mathrm{model}^{25}$ of VEGF focal hyperstimulation delivered by an adenoviral vector (AdVEGF) showed inhibition of MMP-9 mRNA expression in response to doxycycline therapy. Doxycycline proved to be effective at very low doses, with good tolerance and acceptable complication rates. ${ }^{12,17}$ Although it remains a potential target, some authors have postulated that direct VEGF-oriented molecular therapy might be an ineffective or even detrimental alternative due to VEGF's inherent effect on normal vascular and neuronal cells. ${ }^{16,21,24,30,32,33}$

Vascular endothelial growth factor is seen as a possible common pathway molecule in AVM pathogenesis. Thrombospondin-1 (TSP-1), a VEGF-A antagonist, has low levels in AVM-BECs. Inhibition of a TSP-1 transcription repressor, called "inhibitor of DNA-binding protein A" (Id-1), increases TSP-1 levels. Increasing TSP-1 will theoretically inhibit VEGF-A. Recently, microRNA-18a (miR-18a), a short noncoding RNA involved in posttranscriptional regulation of gene expression affecting stability and translation of RNA, was proven to increase TSP-1 in AVM-BECs by inhibiting its inhibitor (Id-1). ${ }^{11,58}$ Under shear arterial blood flow conditions, naked miR18a significantly reduces VEGF-A and VEGF-D release in AVM-BECs and not in normal BECs, demonstrating tissue specificity. MiR-18a normalizes the behavior of AVM-BECs, leading to reduced proliferation and improved tubule formation, enhancing vascular structure and function. Moreover, miR-18a successfully penetrates target cells without additional reagents, allowing for intravenous or endovascular infusion, making it a promising therapeutic option. ${ }^{11,58}$

The effect of radiation on the molecular process of AVM pathophysiology is of particular interest given its known ability, delivered as SRS, to drive endothelial pro- liferation and ultimately AVM obliteration. ${ }^{43}$ Radiation elevates proapoptotic factors, such as p53, p21Waf-1, and mdm- 2 mRNA. Elevation of TGF- $\beta$ and $\alpha$-smooth muscle actin generates fibroblast transformation into myofibroblasts, possibly leading to shrinkage and obliteration of cerebral AVMs. ${ }^{27,28}$ Smooth muscle cell endothelialization with Weibel-Palade bodies is observed in arteries containing von Willebrand factor and P-selectin. ${ }^{52} \mathrm{Ra}-$ diation causes endothelial cells to separate and become disrupted. Increased E-selectin, P-selectin, ICAM-1, and ET-1 lead to leukocyte and platelet increased adherence postirradiation. These adhesion molecules may be potential targets for biological strategies to accelerate intravascular thrombosis. ${ }^{27}$

Using a lipopolysaccharide and soluble tissue factor conjugate (LPS/sTF) in an animal model of vascular targeting was recently described. In that study, 3 different treatment groups were compared. Results showed induced AVM thrombosis in 58\% of subjects receiving SRS plus LPS/sTF, $12 \%$ in subjects undergoing SRS only, and $43 \%$ in those receiving LPS/sTF only. No systemic toxicity or intravascular thrombosis remote from the target region was detected in any of the animal groups. Human trials are still pending. ${ }^{39}$

\section{Conclusions}

A large variety of genetic, molecular, and biological factors are involved in the process of AVM formation. In vivo models such as lines of endothelial cell cultures from AVM specimens are potential areas for research. Understanding molecular targets such as TGF, VEGF, ANGs, and integrins is important in the development of potential drug therapies. Structural and hemodynamic properties also have an effect on the growth and remodeling of AVMs. Interplay between vasculogenesis and flow through nidal vessels causes growth, remodeling, and hemorrhage of AVMs. In the near future, the development of drug therapies, endovascular technology, minimally invasive microsurgical techniques, and proper patient selection will optimize surgical results and clinical outcomes.

\section{Disclosure}

The authors report no conflict of interest concerning the materials or methods used in this study or the findings specified in this paper.

Author contributions to the study and manuscript preparation include the following. Conception and design: Nakaji, RangelCastilla, Russin. Acquisition of data: Rangel-Castilla, Russin, Martinez-del-Campo, Soriano-Baron. Analysis and interpretation of data: Rangel-Castilla, Russin, Martinez-del-Campo. Drafting the article: Nakaji, Rangel-Castilla, Russin, Martinez-del-Campo, Soriano-Baron. Critically revising the article: Nakaji, Rangel-Castilla, Russin, Spetzler. Reviewed submitted version of manuscript: Nakaji, Spetzler. Study supervision: Spetzler.

\section{References}

1. Amin-Hanjani S: ARUBA results are not applicable to all patients with arteriovenous malformation. Stroke 45:15391540,2014 


\section{Rangel-Castilla et al.}

2. Bendok BR, El Tecle NE, El Ahmadieh TY, Koht A, Gallagher TA, Carroll TJ, et al: Advances and innovations in brain arteriovenous malformation surgery. Neurosurgery 74 (Suppl 1): S60-S73, 2014

3. Bhattacharya JJ, Luo CB, Suh DC, Alvarez H, Rodesch G, Lasjaunias P: Wyburn-Mason or Bonnet-Dechaume-Blanc as Cerebrofacial Arteriovenous Metameric Syndromes (CAMS). A new concept and a new classification. Interv Neuroradiol 7:5-17, 2001

4. Bicer A, Guclu B, Ozkan A, Kurtkaya O, Koc DY, Necmettin Pamir M, et al: Expressions of angiogenesis associated matrix metalloproteinases and extracellular matrix proteins in cerebral vascular malformations. J Clin Neurosci 17:232-236, 2010

5. Chen G, Zheng M, Shu H, Zhan S, Wang H, Zhou D, et al: Macrophage migration inhibitory factor reduces apoptosis in cerebral arteriovenous malformations. Neurosci Lett 508: 84-88, 2012

6. Chen W, Young WL, Su H: Induction of brain arteriovenous malformation in the adult mouse. Methods Mol Biol 1135: 309-316, 2014

7. Chen Y, Hao Q, Kim H, Su H, Letarte M, Karumanchi SA, et al: Soluble endoglin modulates aberrant cerebral vascular remodeling. Ann Neurol 66:19-27, 2009

8. Consoli A, Renieri L, Nappini S, Limbucci N, Mangiafico S: Endovascular treatment of deep hemorrhagic brain arteriovenous malformations with transvenous onyx embolization. AJNR Am J Neuroradiol 34:1805-1811, 2013

9. Crawford PM, West CR, Chadwick DW, Shaw MD: Arteriovenous malformations of the brain: natural history in unoperated patients. J Neurol Neurosurg Psychiatry 49:1-10, 1986

10. Crowley RW, Ducruet AF, McDougall CG, Albuquerque FC: Endovascular advances for brain arteriovenous malformations. Neurosurgery 74 Suppl 1:S74-S82, 2014

11. Ferreira R, Santos T, Amar A, Tahara SM, Chen TC, Giannotta SL, et al: MicroRNA-18a improves human cerebral arteriovenous malformation endothelial cell function. Stroke 45:293-297, 2014

12. Frenzel T, Lee CZ, Kim H, Quinnine NJ, Hashimoto T, Lawton MT, et al: Feasibility of minocycline and doxycycline use as potential vasculostatic therapy for brain vascular malformations: pilot study of adverse events and tolerance. Cerebrovasc Dis 25:157-163, 2008

13. Gao P, Zhang H, Ling F: Angiogenic and inflammatory factor expressions in cutaneomeningospinal angiomatosis (Cobb's syndrome): case report. Acta Neurochir (Wien) 153:16571661,2011

14. Graf CJ, Perret GE, Torner JC: Bleeding from cerebral arteriovenous malformations as part of their natural history. J Neurosurg 58:331-337, 1983

15. Gross BA, Du R: Diagnosis and treatment of vascular malformations of the brain. Curr Treat Options Neurol 16:279, 2014

16. Hashimoto T, Lawton MT, Wen G, Yang GY, Chaly T Jr, Stewart CL, et al: Gene microarray analysis of human brain arteriovenous malformations. Neurosurgery 54:410-425, 2004

17. Hashimoto T, Matsumoto MM, Li JF, Lawton MT, Young WL, University of California, San Francisco, BAVM Study Group: Suppression of MMP-9 by doxycycline in brain arteriovenous malformations. BMC Neurol 5:1, 2005

18. Huai C, Song J, Ma Z, Qin X, Li P, Chen H, et al: Allelic variation of the MMP3 promoter affects transcription activity through the transcription factor C-MYB in human brain arteriovenous malformations. PLoS ONE 8:e57958, 2013

19. Itoyama Y, Uemura S, Ushio Y, Kuratsu J, Nonaka N, Wada H, et al: Natural course of unoperated intracranial arteriovenous malformations: study of 50 cases. J Neurosurg 71:805-809, 1989

20. Jane JA, Kassell NF, Torner JC, Winn HR: The natural history of aneurysms and arteriovenous malformations. J Neurosurg 62:321-323, 1985

21. Kim H, Pawlikowska L, Chen Y, Su H, Yang GY, Young WL: Brain arteriovenous malformation biology relevant to hemorrhage and implication for therapeutic development. Stroke 40 (3 Suppl):S95-S97, 2009

22. Kim H, Su H, Weinsheimer S, Pawlikowska L, Young WL: Brain arteriovenous malformation pathogenesis: a responseto-injury paradigm. Acta Neurochir Suppl 111:83-92, 2011

23. Leblanc GG, Golanov E, Awad IA, Young WL, Biology of Vascular Malformations of the Brain NINDS Workshop Collaborators: Biology of vascular malformations of the brain. Stroke 40:e694-e702, 2009

24. Lee CZ, Xue Z, Zhu Y, Yang GY, Young WL: Matrix metalloproteinase-9 inhibition attenuates vascular endothelial growth factor-induced intracerebral hemorrhage. Stroke 38:25632568, 2007

25. Lee CZ, Yao JS, Huang Y, Zhai W, Liu W, Guglielmo BJ, et al: Dose-response effect of tetracyclines on cerebral matrix metalloproteinase-9 after vascular endothelial growth factor hyperstimulation. J Cereb Blood Flow Metab 26:1157-1164, 2006

26. Lee CZ, Young WL: Management of brain arteriovenous malformations. Curr Opin Anaesthesiol 18:484-489, 2005

27. Liu S, Sammons V, Fairhall J, Reddy R, Tu J, Duong TT, et al: Molecular responses of brain endothelial cells to radiation in a mouse model. J Clin Neurosci 19:1154-1158, 2012

28. Major O, Szeifert GT, Fazekas I, Vitanovics D, Csonka E, Kocsis B, et al: Effect of a single high-dose gamma irradiation on cultured cells in human cerebral arteriovenous malformation. J Neurosurg 97 (5 Suppl):459-463, 2002

29. Mast H, Young WL, Koennecke HC, Sciacca RR, Osipov A, Pile-Spellman J, et al: Risk of spontaneous haemorrhage after diagnosis of cerebral arteriovenous malformation. Lancet 350:1065-1068, 1997

30. Merrill MJ, Oldfield EH: A reassessment of vascular endothelial growth factor in central nervous system pathology. J Neurosurg 103:853-868, 2005

31. Mikhak B, Weinsheimer S, Pawlikowska L, Poon A, Kwok PY, Lawton MT, et al: Angiopoietin-like 4 (ANGPTL4) gene polymorphisms and risk of brain arteriovenous malformations. Cerebrovasc Dis 31:338-345, 2011

32. Moftakhar P, Hauptman JS, Malkasian D, Martin NA: Cerebral arteriovenous malformations. Part 1: cellular and molecular biology. Neurosurg Focus 26(5):E10, 2009

33. Moftakhar P, Hauptman JS, Malkasian D, Martin NA: Cerebral arteriovenous malformations. Part 2: physiology. Neurosurg Focus 26(5):E11, 2009

34. Murphy PA, Lam MT, Wu X, Kim TN, Vartanian SM, Bollen AW, et al: Endothelial Notch4 signaling induces hallmarks of brain arteriovenous malformations in mice. Proc Natl Acad Sci U S A 105:10901-10906, 2008

35. Nishida T, Faughnan ME, Krings T, Chakinala M, Gossage JR, Young WL, et al: Brain arteriovenous malformations associated with hereditary hemorrhagic telangiectasia: gene-phenotype correlations. Am J Med Genet A 158A:2829-2834, 2012

36. Novakovic RL, Lazzaro MA, Castonguay AC, Zaidat OO: The diagnosis and management of brain arteriovenous malformations. Neurol Clin 31:749-763, 2013

37. Pawlikowska L, Tran MN, Achrol AS, Ha C, Burchard E, Choudhry S, et al: Polymorphisms in transforming growth factor-beta-related genes ALK1 and ENG are associated with sporadic brain arteriovenous malformations. Stroke 36:22782280, 2005

38. Pollock BE, Gorman DA, Coffey RJ: Patient outcomes after arteriovenous malformation radiosurgical management: results based on a 5- to 14-year follow-up study. Neurosurgery 52:1291-1297, 2003

39. Reddy R, Duong TT, Fairhall JM, Smee RI, Stoodley MA: 
Durable thrombosis in a rat model of arteriovenous malformation treated with radiosurgery and vascular targeting. Laboratory investigation. J Neurosurg 120:113-119, 2014

40. Ross J, Al-Shahi Salman R: Interventions for treating brain arteriovenous malformations in adults. Cochrane Database Syst Rev (7):CD003436, 2010

41. Russin J, Spetzler R: Commentary: The ARUBA Trial. Neurosurgery 75:E96-E97, 2014

42. Saleh M, Carter MT, Latino GA, Dirks P, Ratjen F: Brain arteriovenous malformations in patients with hereditary hemorrhagic telangiectasia: clinical presentation and anatomical distribution. Pediatr Neurol 49:445-450, 2013

43. Sammons V, Davidson A, Tu J, Stoodley MA: Endothelial cells in the context of brain arteriovenous malformations. $\mathbf{J}$ Clin Neurosci 18:165-170, 2011

44. Spetzler RF, Martin NA: A proposed grading system for arteriovenous malformations. J Neurosurg 65:476-483, 1986

45. Spetzler RF, Ponce FA: A 3-tier classification of cerebral arteriovenous malformations. Clinical article. J Neurosurg 114: 842-849, 2011

46. Stapf C, Mast H, Sciacca RR, Berenstein A, Nelson PK, Gobin YP, et al: The New York Islands AVM Study: design, study progress, and initial results. Stroke 34:e29-e33, 2003

47. Starke RM, Komotar RJ, Hwang BY, Hahn DK, Otten ML, Hickman ZL, et al: Systemic expression of matrix metalloproteinase-9 in patients with cerebral arteriovenous malformations. Neurosurgery 66:343-348, 2010

48. Sturiale CL, Puca A, Sebastiani P, Gatto I, Albanese A, Di Rocco C, et al: Single nucleotide polymorphisms associated with sporadic brain arteriovenous malformations: where do we stand? Brain 136:665-681, 2013

49. Sun B, Qiu H, Zhao F, Qiao N, Fan W, Lu D, et al: The rs9509 polymorphism of MMP-9 is associated with risk of hemorrhage in brain arteriovenous malformations. J Clin Neurosci 19:1287-1290, 2012

50. Takagi Y, Aoki T, Takahashi JC, Yoshida K, Ishii A, Arakawa Y, et al: Differential gene expression in relation to the clinical characteristics of human brain arteriovenous malformations. Neurol Med Chir (Tokyo) 54:163-175, 2014

51. Tu J, Karunanayaka A, Windsor A, Stoodley MA: Comparison of an animal model of arteriovenous malformation with human arteriovenous malformation. J Clin Neurosci 17:96102,2010

52. Tu J, Stoodley MA, Morgan MK, Storer KP: Responses of arteriovenous malformations to radiosurgery: ultrastructural changes. Neurosurgery 58:749-758, 2006

53. van Beijnum J, van der Worp HB, Buis DR, Al-Shahi Salman R, Kappelle LJ, Rinkel GJ, et al: Treatment of brain arteriovenous malformations: a systematic review and meta-analysis. JAMA 306:2011-2019, 2011

54. Wautier MP, Boval B, Chappey O, Enjolras O, Wernert N, Merland JJ, et al: Cultured endothelial cells from human arteriovenous malformations have defective growth regulation. Blood 94:2020-2028, 1999

55. Westbroek EM, Pawlikowska L, Lawton MT, McCulloch CE, Young WL, Kim H: Brain-derived neurotrophic factor Val66Met polymorphism predicts worse functional outcome after surgery in patients with unruptured brain arteriovenous malformation. Stroke 43:2255-2257, 2012

56. Yao Y, Yao J, Radparvar M, Blazquez-Medela AM, Guihard PJ, Jumabay M, et al: Reducing Jagged 1 and 2 levels prevents cerebral arteriovenous malformations in matrix Gla protein deficiency. Proc Natl Acad Sci U S A 110:19071-19076, 2013

57. Yoshida K, Ichikawa T, Kurozumi K, Yanai H, Onoda K, Date I: Fatal glioblastoma after Gamma Knife radiosurgery for arteriovenous malformation in a child. J Clin Neurosci 21:1453-1455, 2014

58. Zammar SG, El Tecle NE, El Ahmadieh TY, McClendon J Jr, Comair YG, Bendok BR: A biological approach to treating brain arteriovenous malformations. Neurosurgery 74:N15N17, 2014

Manuscript submitted May 14, 2014.

Accepted July 7, 2014.

Please include this information when citing this paper: DOI: 10.3171/2014.7.FOCUS14214.

Address correspondence to: Peter Nakaji, M.D., c/o Neuroscience Publications, Barrow Neurological Institute, St. Joseph's Hospital and Medical Center, 350 W. Thomas Rd., Phoenix, AZ 85013. email: neuropub@dignityhealth.org. 